\title{
On the accuracy and reproducibility of fiber optic (FO) and infrared (IR) temperature measurements of solid materials in microwave applications
}

\author{
Tomasz Durka ${ }^{1}$, Georgios D Stefanidis ${ }^{1,3}$, Tom Van Gerven ${ }^{2}$ and \\ Andrzej Stankiewicz ${ }^{1}$ \\ ${ }^{1}$ Delft University of Technology, Process \& Energy Department, Intensified Reaction \& Separation \\ Systems, Leeghwaterstraat 44, 2628 CA, Delft, The Netherlands \\ ${ }^{2}$ Department of Chemical Engineering, Katholieke Universiteit Leuven, De Croylaan 46, 3001 Leuven, \\ Belgium \\ E-mail: g.stefanidis@tudelft.nl
}

Received 7 October 2009, in final form 21 January 2010

Published 9 March 2010

Online at stacks.iop.org/MST/21/045108

\begin{abstract}
The accuracy and reproducibility of temperature measurements in solid materials under microwave heating are investigated in this work using two of the most celebrated temperature measurement techniques, namely fiber optic probes (FO) and infrared (IR) sensors. Two solid materials with a wide range of applications in heterogeneous catalysis and different microwave absorbing capabilities are examined: $\mathrm{CeO}_{2}-\mathrm{ZrO}_{2}$ and $\mathrm{Al}_{2} \mathrm{O}_{3}$ particles. We investigate a number of effects ranging from purely technical issues, such as the use of a glass probe guide, over process operation parameters, such as the kind and the volume of the heated sample, to measurement related issues, such as the exact location of the probe in the sample. In this frame, the FO and IR methods are benchmarked. It was found that when using bare FO probes, not only is their lifetime reduced but also the reproducibility of the results is compromised. Using a glass probe guide greatly assists in precise location of the probe in the sample resulting in more reproducible temperature measurements. The FO reproducibility, though, decreases with increasing temperature. Besides, contrary to conventional heating, the sample temperature decreases with decreasing sample mass (and volume) at constant irradiation power level, confirming the volumetric nature of microwave heating. Furthermore, a strongly non-uniform temperature field is developed in the reactor despite the use of a monomode cavity and small amounts of samples. These temperature variations depending on the volume and position can only by detected by FO. In contrast, IR, which actually measures temperature at the exterior of the reactor wall, remains nearly insensitive to them and consistently underestimates the real temperature in the reactor. The modeler and the experimentalist should be rather circumspect in accepting the IR output as a representative reactor temperature.
\end{abstract}

Keywords: microwaves, temperature measurement, fiber optic, infrared, catalyst

\section{Introduction}

For the past few years a great deal of interest in microwave technology for chemical applications has been observed. Year

\footnotetext{
3 Author to whom any correspondence should be addressed.
}

by year the number of publications grows continuously. This alternative way of providing energy to carry out chemical reactions has been widely investigated and in the coming years will probably become the most often used organic synthesis technique in the chemical laboratory [1]. For 
Table 1. Comparison of the most popular temperature measurement techniques for microwave applications ${ }^{\mathrm{a}}$.

\begin{tabular}{|c|c|c|c|}
\hline & Radiation pyrometer & Fiber optic thermometer & Thermocouple \\
\hline Measurement range $\left({ }^{\circ} \mathrm{C}\right)$ & -40 to 2000 & -200 to 2000 & -270 to 2300 \\
\hline Accuracy & $\pm 2{ }^{\circ} \mathrm{C}$ & $\pm 0.5^{\circ} \mathrm{C}$ & $\pm 0.5- \pm 2{ }^{\circ} \mathrm{C}$ \\
\hline Response speed & Very fast & Fast/very fast & Very fast \\
\hline Interference with MW field & No & $\mathrm{No}^{\mathrm{b}}$ & $\mathrm{Yes}^{\mathrm{c}}$ \\
\hline Cost & High & Mid to high & Very low \\
\hline Drawbacks & $\begin{array}{l}\text { - Dependent on the reactor material } \\
\text { - Sensitive to the emissivity } \\
\text { magnitude } \\
\text { - Suitable only for surface } \\
\text { temperature measurements }\end{array}$ & $\begin{array}{l}\text { - Probe delicate and sensitive to } \\
\text { contamination/degradation }\end{array}$ & $\begin{array}{l}\text { - Interferes with the microwave field } \\
\text { - Self-heated in a microwave field }\end{array}$ \\
\hline
\end{tabular}

${ }^{a}$ References [7, 19].

${ }^{\mathrm{b}}$ As long as the probe does not contain metal coating.

${ }^{\mathrm{c}}$ In specific cases can be significantly minimized.

many chemical reactions, a large improvement in conversion and/or selectivity and a reduction in reaction time have been observed [2-6]. Unfortunately, many investigators disregard the important aspect of appropriate temperature measurement.

Correct temperature measurement of the radiated materials is indeed the most important problem in both monomode and multimode microwave systems. The most popular temperature measurement techniques used during conventional heating, such as infrared pyrometers, optical fiber thermometry or thermocouple, can be used during microwave processing with appropriate modification. Their most important features are summarized in table 1 . It is noted that temperature measurements under microwave conditions require special attention since the temperature measurement device should not disturb the microwave field, be affected by the field, or significantly disturb the thermal distribution within the sample [7].

Using conventional thermocouples is strongly discouraged due to interferences between the electromagnetic field and the metallic probe, which can potentially lead to sparking. Moreover, Pert et al [7] placed a thermocouple into an empty microwave cavity with $150 \mathrm{~W}$ applied power at $2.45 \mathrm{GHz}$ and found that the thermocouple indication was $100{ }^{\circ} \mathrm{C}$ while the ambient temperature was only $26{ }^{\circ} \mathrm{C}$. This supports the fact that the thermocouple itself can be heated directly by the microwave field. The sparking problem can be partially mitigated via shielding and grounding; the risk cannot be completely avoided, though [8]. Some authors proposed to measure temperature with conventional thermocouple immediately after switching off the magnetron, but later experiments showed that this method considerably underestimated the temperature measured under microwave radiation $[9,10]$.

The most popular and widely used method for control of the reaction temperature in microwave applications is infrared (IR) thermometry. Two IR measurement techniques are commonly used, namely IR sensors built into microwave ovens and external IR cameras. Both techniques induce different problems depending on the particular application. It has been suggested by Stuerga and Gillard [11] that for heterogeneous solvent-free processes the IR measurement is more reliable than other techniques as it is non-invasive and independent of the thermal properties of the probe, i.e. its thermal capacity and thermal resistance. On the other hand, it has been reported that using a conventional IR sensor is not appropriate if a very accurate comparative study has to be performed [1, 12]. The IR technique, by nature, allows us to measure temperature only on the surface of the reaction vessel or on the top surface of the reaction mixture. This makes the IR measurement accurate only for very thin sample layers, where the surface temperature is close to the bulk temperature. Another issue with IR sensors is the need for frequent recalibration due to their sensitivity to the ambient conditions and due to the dependence of the measured temperature on the material properties of the reaction vessel. Aside from IR sensors, Bogdal and Lukasiewicz $[9,13]$ measured the temperature of a well-absorbing solid material immersed in a low-absorbing solvent using a thermovision camera. Although the solid surface had a higher temperature than the boiling point of the surrounding solvent, no boiling of the solvent was observed even near the surface. Moreover, due to the inverse temperature gradient, the temperature recorded near the wall was lower than that in the bulk of the solvent, although the contrary would be expected due to the hotter solid surface. This example shows how critical it is to assure accurate temperature measurements in order to avoid not only quantitatively but also qualitatively misleading conclusions and trends in the underlying physics of the process under investigation.

Another temperature measurement method, widely used in microwave-assisted chemistry, is fiber-optics thermometry (FO). This method presents many advantages compared to IR. (1) The FO measurement is independent of the reaction vessel material, (2) there is no need for recalibration before each experiment and (3) there is the possibility of measuring the temperature inside the reaction vessel at various positions. It appears, therefore, that the FO technique offers a significant improvement. However, using FO requires that particular attention be paid to sensor positioning in order to avoid damaging the probe and to ensure reproducible results. Although it is generally accepted that the application of FO for temperature measurement under microwave irradiation is one of the best techniques [12, 14, 15], Bogdal et al [14] have shown that in viscous homogeneous reaction media or heterogeneous solid samples the temperature obtained via FO is only 'local' temperature-different from the average bulk temperature. 
Finally, it should be remarked that even in homogeneous liquid systems, the available technologies do not provide the appropriate tools to measure temperature in the micrometer scale; the presence of meso/microscopic hot spots is often regarded as a thermal effect that brings about the significant acceleration in reaction rates observed under microwave heating. Both IR and FO measure temperature at the macroscale and therefore the so-called meso/microscopic hot spots remain out of the measurement range. This paper discusses temperature measurements in microwave applications, where solid particles are involved (e.g. in gassolid/liquid-solid heterogeneous catalytic systems). Uniform heating of solid materials under microwave conditions is of paramount importance but difficult to achieve. In cases of reactors with fixed solid (catalytic) particles, high temperature gradients (in 3D) inside the reactor bed may develop, as opposed to liquid phase reactors, where stirring conditions can mitigate spatial temperature gradients. Therefore, multipoint temperature monitoring is crucial. Nonetheless, measuring temperature in solid materials irradiated by electromagnetic waves is not a trivial task as a number of commonly applicable techniques are often impractical due to the restrictions arising from the design of the microwave applicator (limited access to the sample), the immunity of the sensor and possible loss of contact between the probe and the solids. Finally, the stochastic geometry inside the bed, due to random packing, results in reactor-microwave field interactions, which are very difficult, if not impossible, to predict and have implications in the controllability and reproducibility of the temperature field.

The reproducibility and accuracy of the two most widely used techniques, FO and IR, are verified experimentally in this work.

\section{Materials and methods}

Experiments were performed in a monomode microwave oven (Discovery-CEM Company) in $10 \mathrm{ml}$ Pyrex glass vials (emissivity of 0.92 [16]) under ambient pressure and a constant microwave power of $10 \mathrm{~W}$ for $40 \mathrm{~min}$. The cooling mode was switched off during the tests. Although Pyrex is not completely transparent for electromagnetic waves, heating experiments on an empty vial showed that for the microwave power applied in this study, no significant temperature rise was observed. The temperature was measured both via the built-in IR sensor of the device and via an external FO sensor (FISO Technologies-FOT-L-BA) simultaneously. The fiber optic sensor used in this study is a single-point sensor operating based on the Fabry-Pérot white-light interferometry technique. The sensor consists of two parallel perfectly flat semi-reflecting mirrors positioned at a certain distance from each other (a few nanometers). The light passing through the first mirror is reflected backward and forward between the mirrors. At each reflection a fraction of light is lost; therefore, each beam leaving the interferometer is less intense. All reflected beams travel through the optical fiber to a signal conditioner, where the light is separated by a $2 \times 2$ coupler. The light sent to the light source is lost, whereas the rest of the light is directed and spread over a Fizeau wedge to reconstruct the interference pattern, which is detected and recorded by a charge coupled device (CCD). By finding the maximum intensity of the interference pattern related to changes of the optical path differences (generated by a temperature change) the temperature value can be calculated [17]. The temperature measured by the FO probe was recorded with a multichannel fiber-optic signal conditioner (UMI 4), whereas the temperature measured by the IR sensor was read out from the display of the microwave oven. The IR sensor used in this study is a typical two-piece infrared temperature measurement system with separate electronics. Since the sensor is an integral part of the microwave applicator, it was considered as optimally configured by the manufacturer. The sensor operates over the spectrum 8-14 $\mu \mathrm{m}$. Depending on the surface of the reactor used, manual correction of the emissivity and transmission over the range 0.1-1.1 may be necessary. These parameters have not been adjusted in our work, though, since the experiments were performed with testing vials delivered by the manufacturer of the microwave applicator and thus, they were considered optimized. The sensor allows temperature measurements between $-40{ }^{\circ} \mathrm{C}$ and $600{ }^{\circ} \mathrm{C}$ with an accuracy of $1 \%$ over the entire range. The optical resolution of the used sensor is 10:1 and the spot size at $0 \mathrm{~mm}$ distance is $5 \mathrm{~mm}$. Both sensors used in this study have been bought calibrated by the manufacturer.

Two undried catalytic supports, $\mathrm{CeO}_{2}-\mathrm{ZrO}_{2}$ and $\mathrm{Al}_{2} \mathrm{O}_{3}$, commonly used for steam reforming of oxygenated fuels (the reaction under investigation in our project), were employed for these tests. In each test, $2 \mathrm{~g}$ of the support was used unless otherwise stated. The $\mathrm{CeO}_{2}-\mathrm{ZrO}_{2}$ support was prepared by precipitation with an ammonia solution (32 wt\%) from 0.2 mol solutions of cerium and zirconium nitrates (Aldrich, purity $99 \%$ ). After filtration and subsequent washing with de-ionized water and drying at $120{ }^{\circ} \mathrm{C}$ for $8 \mathrm{~h}$, the hydroxide

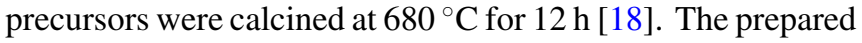
support was then crushed using a mortar and pestle and sieved to the desired fraction. The fraction between 70 and $125 \mu \mathrm{m}$ was used for all tests. The $\mathrm{Al}_{2} \mathrm{O}_{3}$ support was commercially available (Alfa Aesar, purity 99.5\%). As mentioned above, the experimental results presented in this work were obtained with the support that was not dried before use. Some limited experiments with dried alumina samples (at $200{ }^{\circ} \mathrm{C}$ for several days) were also performed and resulted in lower steady-state temperatures (up to $35^{\circ} \mathrm{C}$ ). Since the main aim in this work is to explore spatial temperature non-uniformities and benchmark FO and IR measurements, the results with dried alumina are not presented here. It is finally noted that all tests were repeated at least three times to improve the accuracy of the measured data.

\section{Experimental details}

Five series of experiments, described below, were performed to elucidate different effects on temperature measurements under microwave heating. The most important findings are summarized in table 2 . 
Table 2. Summary of experimental tests.

\begin{tabular}{|c|c|c|c|c|c|}
\hline $\begin{array}{l}\text { Experiment } \\
\text { no }\end{array}$ & Sample & Effect & Major observation & $\begin{array}{l}\text { Maximum } \\
\text { Temperature } \\
\text { recorded by } \\
\text { IR }\left({ }^{\circ} \mathrm{C}\right)\end{array}$ & $\begin{array}{l}\text { Maximum } \\
\text { Temperature } \\
\text { recorded by } \\
\text { FO }\left({ }^{\circ} \mathrm{C}\right)\end{array}$ \\
\hline 1 & $2 \mathrm{~g} \mathrm{CeO}_{2}-\mathrm{ZrO}_{2}$ & Without probe guide & No reproducible measurements & 70 & $70-80$ \\
\hline 2 & $2 \mathrm{~g} \mathrm{CeO}_{2}-\mathrm{ZrO}_{2}$ & With probe guide & Reproducible measurements & 65 & 70 \\
\hline 3 & $2 \mathrm{~g} \mathrm{Al}_{2} \mathrm{O}_{3}$ & Kind of heated sample & $\begin{array}{l}\text { The FO reproducibility deteriorates } \\
\text { with increasing temperature }\end{array}$ & 90 & 140 \\
\hline 4 & $0.5 \mathrm{~g} \mathrm{Al}_{2} \mathrm{O}_{3}$ & Sample volume & $\begin{array}{l}\text { - The FO recorded temperature } \\
\text { depends on the sample volume } \\
\text { - IR significantly under predicts the } \\
\text { reactor temperature } \\
\text { - IR is relatively insensitive to } \\
\text { variations in the amount of solids }\end{array}$ & 95 & 110 \\
\hline 5 & $2 \mathrm{~g} \mathrm{CeO}_{2}-\mathrm{ZrO}_{2}$ & $\begin{array}{l}\text { Temperature uniformity in } \\
\text { the axial direction }\end{array}$ & $\begin{array}{l}\text { - Temperature non-uniformity in the } \\
\text { axial direction }\end{array}$ & $62^{\mathrm{a}}$ & $63-69$ \\
\hline 6 & $2 \mathrm{~g} \mathrm{Al}_{2} \mathrm{O}_{3}$ & $\begin{array}{l}\text { Temperature uniformity in } \\
\text { the axial direction }\end{array}$ & $\begin{array}{l}\text { - The IR sensor consistently } \\
\text { underestimates the actual temperature } \\
\text { at various positions inside the reactor }\end{array}$ & 90 & $128-138^{\mathrm{a}}$ \\
\hline 7 & $2 \mathrm{~g} \mathrm{Al}_{2} \mathrm{O}_{3}$ & $\begin{array}{l}\text { Temperature uniformity in } \\
\text { the radial direction }\end{array}$ & $\begin{array}{l}\text { - Temperature non-uniformity in the } \\
\text { radial direction. Maximum temperature } \\
\text { at the center } \\
\text { - Same conclusion for the IR method as } \\
\text { in experiment } 6\end{array}$ & 100 & $110 / 140^{\mathrm{b}}$ \\
\hline
\end{tabular}

\footnotetext{
${ }^{a}$ Depends on the probe position.

${ }^{\mathrm{b}}$ Depends on the sensor position.
}

\subsection{Effect of the probe guide}

The first experiment was performed with a $\mathrm{CeO}_{2}-\mathrm{ZrO}_{2}$ sample. The sample was weighed and then inserted in the glass testing vial. The vial was closed with a Teflon cap. The FO was introduced in the sample (through a small opening in the cap) and positioned at the center by visual inspection. After each test, the vial was removed from the microwave cavity and put in a sample holder to cool down to ambient temperature. The cooled sample was then removed from the vial, weighed and placed back in the vial for the next test. As the FO sensor is more sensitive and accurate $\left(0.1^{\circ} \mathrm{C}\right)$, the temperature measured by the FO probe was noted every $10 \mathrm{~s}$ during the first $10 \mathrm{~min}$ of the experiment and then every $1 \mathrm{~min}$ until the end of the test. Due to the measuring accuracy of the IR sensor being coarser (only $1{ }^{\circ} \mathrm{C}$ ), the temperature readout from the microwave unit was noted with random frequency, but at least once every $3 \mathrm{~min}$.

Figure 1 shows that the temperature measured by the IR sensor is clearly lower than that measured by FO. Moreover, two tests with FO gave temperature results that differ up to $9{ }^{\circ} \mathrm{C}$. It is not surprising that the IR sensor ensures better reproducibility than FO, as it is permanently attached to the microwave unit and is capable of measuring temperature at a precisely defined spot (i.e. at the exterior of the glass vial bottom). On the other hand, the position of the FO probe in two different experiments cannot be exactly the same as the sensor is flexible and tends to bend. Moreover, insertion of the delicate probe in a bed of solid particles results in partial degradation of its material.

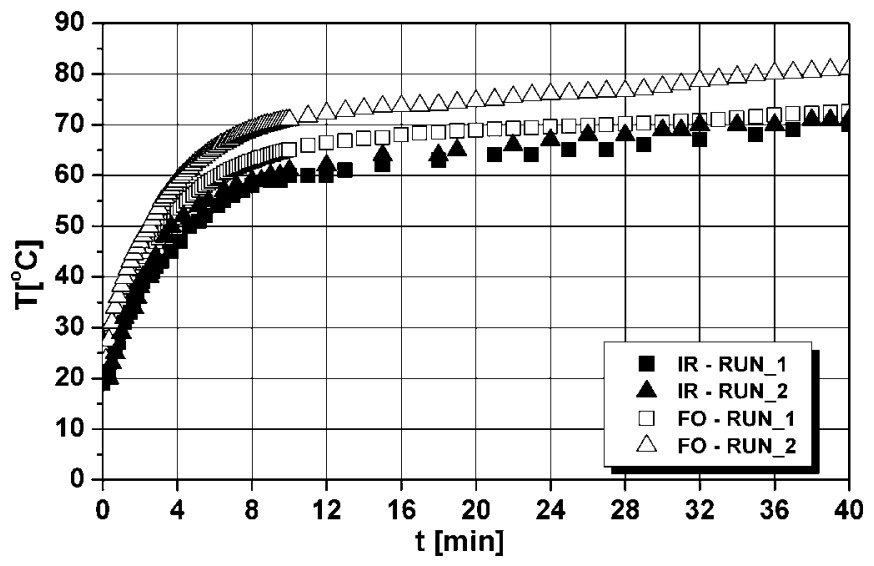

Figure 1. Comparison of temperature profiles obtained with IR and $\mathrm{FO}$ for a $2 \mathrm{~g} \mathrm{CeO}_{2}-\mathrm{ZrO}_{2}$ sample. The $\mathrm{FO}$ recorded temperature is measured on the vertical centerline $6 \mathrm{~mm}$ above the bottom of the glass vial. Only the bare probe without glass protection was inserted in the sample.

To achieve more reproducible results and protect the probe against breaking, the rest of the experiments were performed with the FO probe introduced into the sample through a $2 \mathrm{~mm}$ O.D. capillary made from borosilicate glass (figure 2). This 'probe guide' was placed inside the vial in such a way that the position of the FO probe could change in the axial direction if needed. Although it was possible to move the sensor inside the glass capillary, the FO probe fitted the capillary tightly enough to prevent position change during the measurements. To ensure the correct position, marks were put both on the probe 


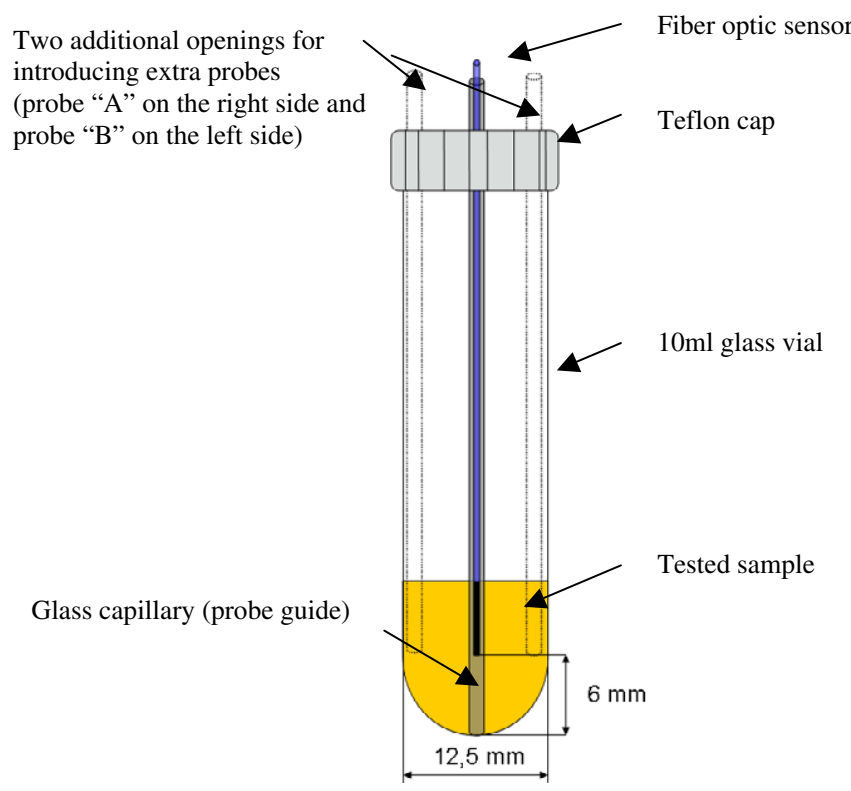

Figure 2. Schematic view of the $10 \mathrm{ml}$ glass vial containing $2 \mathrm{~g}$ of solid sample with the introduced fiber optic sensor.

(This figure is in colour only in the electronic version)

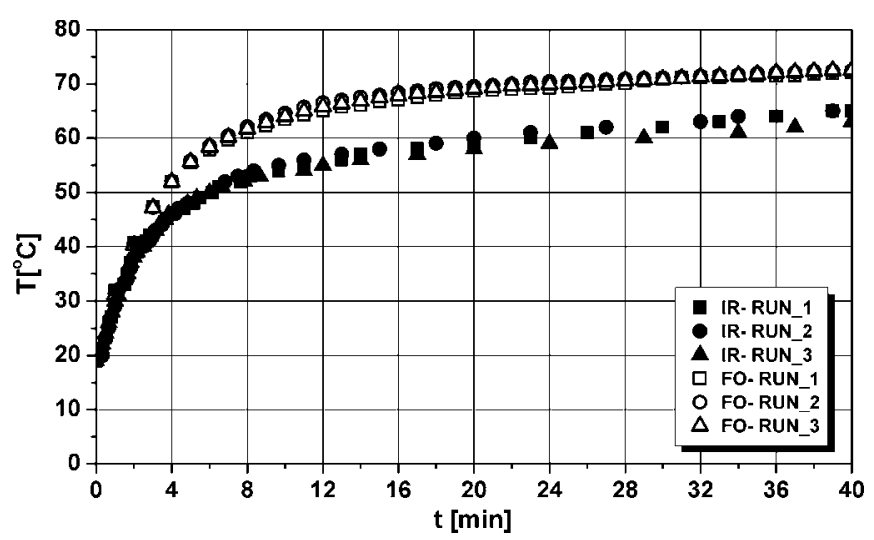

Figure 3. Comparison of temperature profiles obtained with IR and $\mathrm{FO}$ for a $2 \mathrm{~g} \mathrm{CeO}_{2}-\mathrm{ZrO}_{2}$ sample. The $\mathrm{FO}$ recorded temperature is measured on the vertical centerline $6 \mathrm{~mm}$ above the bottom of the glass vial. Now the FO probe is placed in a glass probe guide.

and on the glass capillary. At the desired probe location, the two marks overlapped each other. All subsequent experiments were performed with the probe (in the glass capillary) situated $6 \mathrm{~mm}$ above the bottom of the vial unless otherwise stated. This specific location of the tip of the FO probe was chosen such that the side effects of the vial walls were minimized and the central position of the probe inside the sample was ensured. It should be noted here that the spatial temperature measurements in this work refer to the distance of the tip of the probe from the bottom of the vial. It is stressed, however, that the set of mirrors of the sensor interferometer is located $\sim 2 \mathrm{~mm}$ above the tip of the probe. Figure 3 shows that when a glass probe guide was applied (open symbols) the reproducibility of temperature measurements by FO was significantly improved in comparison to results obtained without the probe guide (open symbols, figure 2). It can be seen that the temperature

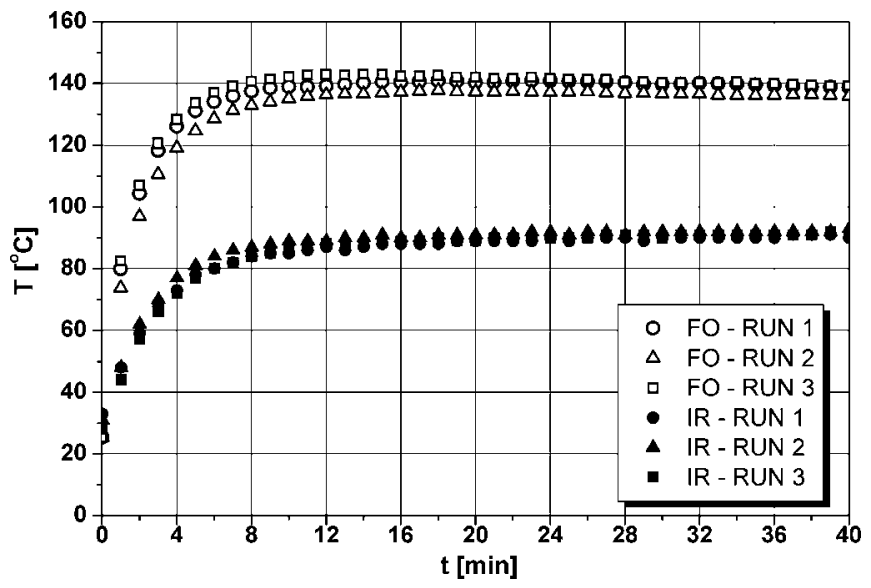

Figure 4. Comparison of temperature profiles obtained with IR and FO for a $2 \mathrm{~g} \mathrm{Al}_{2} \mathrm{O}_{3}$ sample. The $\mathrm{FO}$ recorded temperature is measured on the vertical centerline $6 \mathrm{~mm}$ above the bottom of the glass vial.

profiles with FO in all three runs of figure 3 virtually overlap $\left(0.5{ }^{\circ} \mathrm{C}\right.$ margin of error). Finally, it was observed that application of probe protection greatly increases the lifetime of the FO probe.

\subsection{Effect of the heated sample}

$\mathrm{CeO}_{2}-\mathrm{ZrO}_{2}$ is not a good microwave energy absorber. Therefore, it was decided to also perform another set of experiments with a different material. The aim of changing the test material was to investigate whether its ability to absorb microwave energy has any influence on the reproducibility of the temperature measurements. From a wide palette of different catalytic supports for ethanol steam reforming $\mathrm{Al}_{2} \mathrm{O}_{3}$ was chosen. Although $\mathrm{Al}_{2} \mathrm{O}_{3}$ is described in the literature as a low microwave energy absorber, it has been concluded experimentally that it is a much better absorber than $\mathrm{CeO}_{2}-$ $\mathrm{ZrO}_{2}$. Figure 4 shows that the measurement reproducibility for three samples tested in sequence was $5{ }^{\circ} \mathrm{C}$ for both the FO and IR sensors at steady state. This error is almost the same as that obtained with IR at the low temperature experiments when testing $\mathrm{CeO}_{2}-\mathrm{ZrO}_{2}$ but approximately one order of magnitude higher than that obtained with $\mathrm{FO}$ in the case of $\mathrm{CeO}_{2}-\mathrm{ZrO}_{2}\left(5^{\circ} \mathrm{C}\right.$ versus $\left.0.5{ }^{\circ} \mathrm{C}\right)$. Therefore, it is concluded that the reproducibility with the FO method deteriorates with increasing temperature (better microwave absorbers). Besides, figure 4 shows that the temperature recorded with the IR method is $\sim 45-50{ }^{\circ} \mathrm{C}$ lower than that with the more reliable FO method at steady state. This should be contrasted to $\sim 10{ }^{\circ} \mathrm{C}$ difference in figure 3 displaying experiments with $\mathrm{CeO}_{2}-\mathrm{ZrO}_{2}$ at a lower temperature level and manifests an increasing discrepancy between the two methods as the temperature level increases. It is remarked here that the Discover system is tailor made for organic synthesis with solvents under magnetic stirring conditions. Therefore, it can be expected that since the solid particles in our work are not stirred, discrepancies between the temperature readings of the FO and the IR sensors will occur. However, in a fixed bed reactor, such as the one we study, the catalytic 


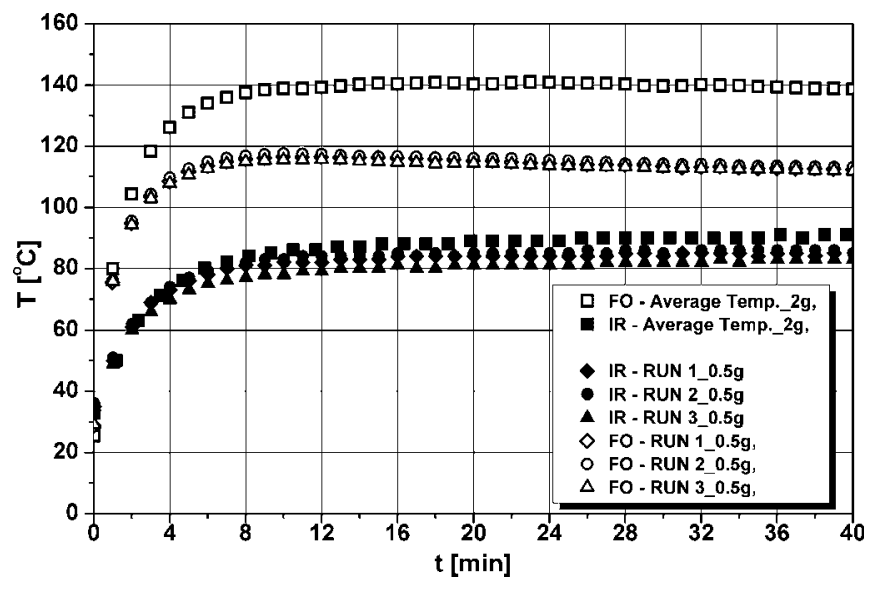

Figure 5. Comparison of temperature profiles obtained with IR and FO for $0.5 \mathrm{~g}$ and $2 \mathrm{~g} \mathrm{Al}_{2} \mathrm{O}_{3}$ samples. The $\mathrm{FO}$ recorded temperature is measured on the vertical centerline $6 \mathrm{~mm}$ above the bottom of the glass vial.

support is inherently static and thus the same issue will actually be present in other types of commercial monomode and multimode microwave cavities as well. To this end, it is one of the targets of this work to identify the problem and quantify the discrepancies between the actual internal temperature measurements with the optical fibers and the output of the infrared thermometer.

\subsection{Effect of the sample volume}

Due to $\mathrm{Al}_{2} \mathrm{O}_{3}$ having a lower volumetric density than $\mathrm{CeO}_{2}-$ $\mathrm{ZrO}_{2}$, a larger volume of $\mathrm{Al}_{2} \mathrm{O}_{3}$ is irradiated when using equal mass samples, as was the case in the previous section. This difference may affect the sample temperature since microwave energy provides volumetric heating $[5,6]$. Therefore, another set of experiments was performed using IR and FO with a smaller amount of $\mathrm{Al}_{2} \mathrm{O}_{3}$ sample $(0.5 \mathrm{~g})$ in order to keep the volume equal to that of $2 \mathrm{~g}$ of $\mathrm{CeO}_{2}-\mathrm{ZrO}_{2}$. Figure 5 presents the sample temperature measured by IR and FO as a function of time for the two supports. Several interesting conclusions are obtained. (1) The temperature measured by the FO probe is significantly lower (by $\sim 30^{\circ} \mathrm{C}$ ) in the $0.5 \mathrm{~g}$ sample than in the $2 \mathrm{~g}$ one thus confirming the volumetric character of microwave heating. Furthermore, the CEM Discover has an electric field maximum at the highest part of the vial, which may result in a more effective interaction between the electromagnetic field and the sample as the sample volume increases. It should be underscored here that in conventional heating the reverse effect is expected; application of equal amount of power to a smaller sample would increase its temperature as the total heat capacity decreases. (2) Same as in section 3.2, the IR sensor predicts significantly lower temperatures $\left(\sim 30^{\circ} \mathrm{C}\right)$ compared to the FO method and (3) the IR sensor is relatively insensitive to variations in the amount of solids; the temperature registered by IR in case of the $0.5 \mathrm{~g}$ sample is only $5-7{ }^{\circ} \mathrm{C}$ lower than that of the $2 \mathrm{~g}$ sample (figure 5). Physically counterintuitive notwithstanding, it is actually not surprising if one bears in mind that the IR sensor actually measures temperature at the exterior of the vial glass bottom rather than in the sample itself.

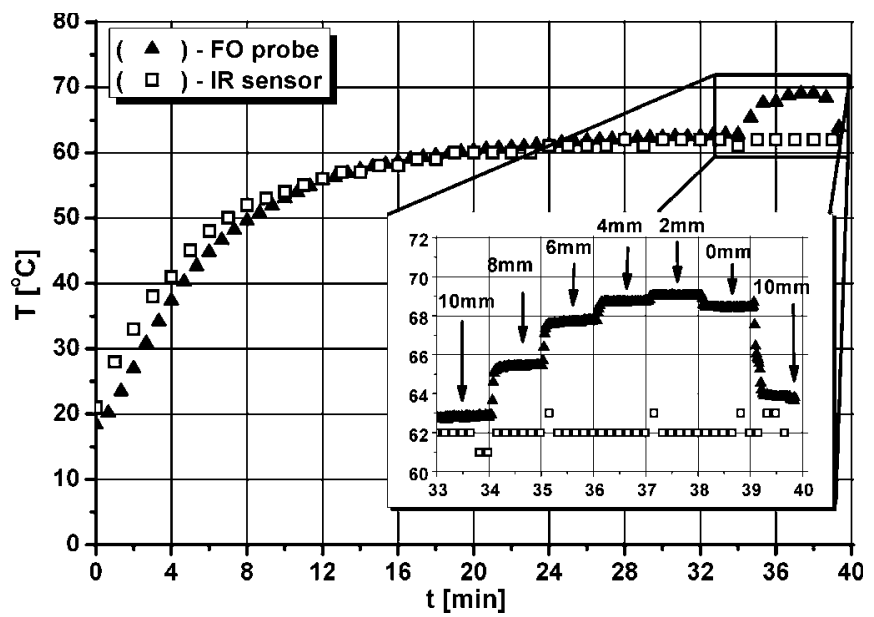

Figure 6. Comparison of temperature profiles obtained with IR and FO for a $2 \mathrm{~g} \mathrm{CeO}_{2}-\mathrm{ZrO}_{2}$ sample. The FO recorded temperature is measured on the vertical centerline of the glass vial. The inset shows the temperature distribution along the vertical centerline at steady state.

\subsection{Effect of the vertical (axial) position}

To evaluate temperature uniformity a set of experiments was performed in which the position of the FO probe varies along the vertical centerline. At the beginning of each run, the FO sensor is located $10 \mathrm{~mm}$ above the bottom of the vial. After 30 min of irradiation, when the sample temperature reaches steady state, the position of the probe is lowered by $2 \mathrm{~mm}$ (i.e. a position located $8 \mathrm{~mm}$ above the glass bottom). As the response time of the FO is relatively short, the new temperature was measured within a few seconds and, subsequently, a new steady state temperature was reached. After one minute, the position of the sensor was changed again to the next position situated $2 \mathrm{~mm}$ below the previous one. This procedure was repeated until the sensor was situated exactly at the bottom of the vial. At the end of the experiment, after the sensor had been located at the bottom of the vial for $1 \mathrm{~min}$, the position was changed back to the first position of $10 \mathrm{~mm}$.

Figure 6 shows the results of this experimental procedure in terms of temperature versus time in the event of $\mathrm{CeO}_{2}-$ $\mathrm{ZrO}_{2}$ support using an FO probe and an IR sensor. The inset in figure 6 is a zoom-out of the upper-right portion of the graph and is meant to present clearly the temperature variation as the position of the FO probe changes. An ascending temperature trend is observed as the FO probe moves deeper in the sample and a maximum $\Delta T$ of $6{ }^{\circ} \mathrm{C}$ is found along the vertical axis; this $\Delta T$ is not negligible considering that it characterizes a very short sample length of $1 \mathrm{~cm}$ and is $\sim 10 \%$ of the absolute temperature recorded $\left(\sim 60{ }^{\circ} \mathrm{C}\right)$. It is also surprising that at the $0 \mathrm{~mm}$ position (the sensor touches the glass wall from the inside) the temperature measured by the FO probe, on the inside wall of the vial, is quite a bit higher than the temperature measured on the outside, by the IR sensor $\left(>6{ }^{\circ} \mathrm{C}\right.$ difference). Albeit the temperature measured on the inside should be higher than outside due to the inverse temperature gradient in microwave heating, such a large difference was not expected after $35 \mathrm{~min}$ of radiation when the temperature profile had already reached steady state. 


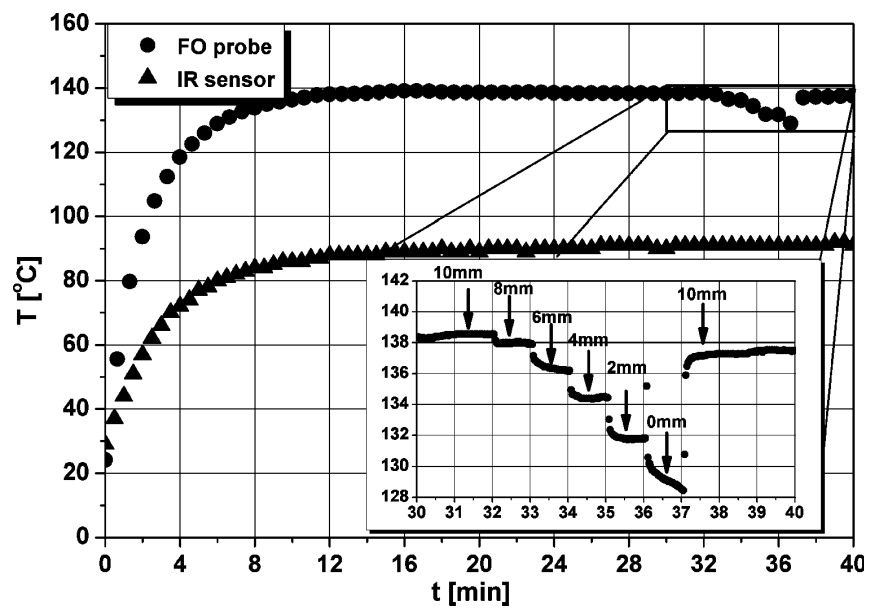

Figure 7. Comparison of temperature profiles obtained with IR and FO for a $2 \mathrm{~g} \mathrm{Al}_{2} \mathrm{O}_{3}$ sample. The $\mathrm{FO}$ recorded temperature is measured on the vertical centerline of the glass vial. The inset shows the temperature distribution along the vertical centerline at steady state.

Figure 7 is the counterpart of figure 6 in the case of $\mathrm{Al}_{2} \mathrm{O}_{3}$. Unlike $\mathrm{CeO}_{2}-\mathrm{ZrO}_{2}$, a descending temperature trend is now observed as the probe moves deeper in the sample. The maximum temperature difference along the height of the sample is now $\sim 10^{\circ} \mathrm{C}$. Despite the decrease, the temperature measured by the $\mathrm{FO}$ probe on the internal glass wall of the vial bottom is $\sim 35^{\circ} \mathrm{C}$ higher than the temperature measured at the same time by the IR sensor on the outside of the vial. The take-home message from this experimental parametric study with respect to the axial FO probe position is twofold. (1) The temperature field obtained when irradiating even small amounts of solid particles in monomode cavities is nonuniform. Multiple-coordinate measurement is required to map out the reactor temperature. (2) The IR sensor consistently underestimates the actual temperature at various positions inside the reactor. The modeler and the experimentalist should be rather circumspect in accepting the IR output as a representative reactor temperature.

\subsection{Effect of the horizontal (radial) position}

In this section, we investigate temperature variation in the horizontal plane (radial direction). Temperature was measured with three FO probes inside the sample of $2.5 \mathrm{~g}$ crushed $\mathrm{Al}_{2} \mathrm{O}_{3}$ pellets. Three fiber optic probes were introduced into the tested sample, via glass capillaries, in three positions being on the left side near the vial wall, in the middle (as in the previous experiments), and on the right side near the vial wall (figure 2). All probes measure temperature simultaneously on the same horizontal plane $6 \mathrm{~mm}$ above the bottom of the vial. The temperature measured by IR, on the outside wall of the bottom of the vial, has been recorded as well.

Figure 8 presents the horizontal temperature distribution, as recorded by FO, as well as the IR indication versus time. The probe on the right side is designated as 'FO-Right', the probe in the middle as 'FO-Center' and the probe on the left side as 'FO-Left'. The highest temperature is reached at the center

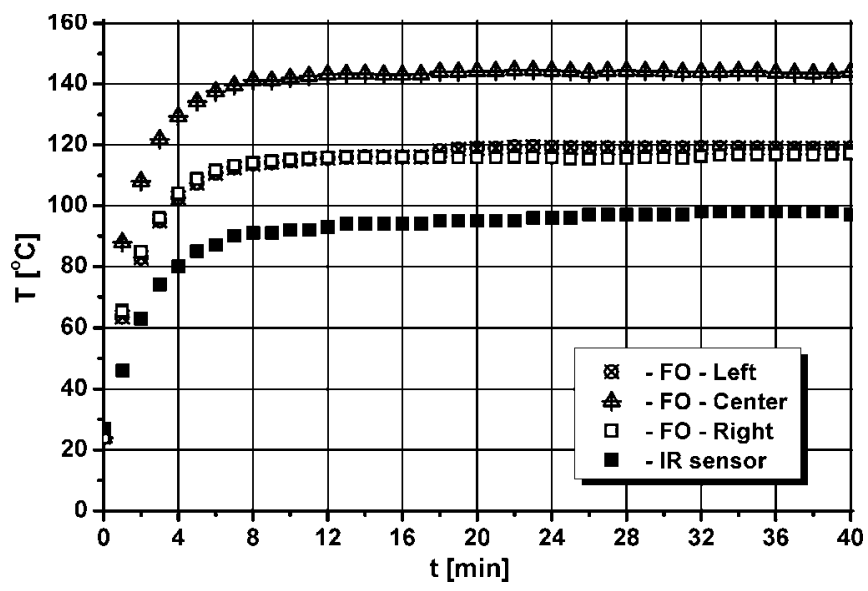

Figure 8. Horizontal temperature distribution profiles obtained with FO inside a $2 \mathrm{~g} \mathrm{Al}_{2} \mathrm{O}_{3}$ sample $6 \mathrm{~mm}$ above the bottom of the glass vial. The black square dots denote the IR temperature indication.

of the sample (figure 8). This is not surprising given that the cavity is designed such that the maximum electric field strength occurs at the center. The two side probes show almost the same temperature at steady state (nearly symmetrical profile), which is $\sim 40{ }^{\circ} \mathrm{C}$ lower than that in the middle. Moreover, the IR indications (solid square symbols) are always quite a bit lower than the FO indications. All in all, the findings here confirm the conclusions of the previous section, which are the presence of temperature non-uniformity not only in the axial but also in the radial direction as well as the inability of the IR method to yield reliable reactor temperature indications.

\section{Conclusions}

Two of the most celebrated temperature measurement techniques (i.e. fiber optic probes (FO) and infra red (IR) sensors) have been benchmarked in the context of microwave heating of solid particles $\left(\mathrm{CeO}_{2}-\mathrm{ZrO}_{2}\right.$ and $\mathrm{Al}_{2} \mathrm{O}_{3}$ particles) with a number of important applications in heterogeneous catalysis. It was found that when using bare FO probes their lifetime is reduced and the reproducibility of the results is compromised. Using a glass probe guide greatly assists in precise positioning of the probe and thus in obtaining reproducible temperature measurements. The FO reproducibility, though, decreases with increasing temperature level. Besides, contrary to conventional heating, the sample temperature decreases with decreasing sample mass (and volume) at constant irradiation power level confirming the volumetric nature of microwave heating. This temperature change can be detected by an FO probe immersed in the sample; on the other hand, IR remains nearly insensitive to it, as it actually measures temperature at the exterior of the vial glass wall. Furthermore, significant temperature non-uniformities were found by using FO in both the axial and radial directions despite the use of a monomode cavity and the small amounts of samples tested. This indicates that temperature measurements at multiple coordinates are requisite for obtaining the temperature map in the reactor. 
Once again, IR was unable to capture these spatial variations and consistently underestimated the real temperature at various positions in the reactor.

\section{References}

[1] Herrero M A, Kremsner J M and Kappe C O 2008 Nonthermal microwave effects revisited: on the importance of internal temperature monitoring and agitation in microwave chemistry J. Org. Chem. 73 36-47

[2] Loupy A (ed) 2002 Microwaves in Organic Synthesis 1st edn (Weinheim, Germany: Wiley-VCH)

[3] Hayes B L 2002 Microwave Synthesis: Chemistry at the Speed of Light (Matthews, USA: CEM Publishing)

[4] Lidstrom P et al 2001 Microwave assisted organic synthesis-a review Tetrahedron 57 9225-83

[5] Hoz A D L, Diaz-Ortiz A and Moreno A 2005 Microwaves in organic synthesis. Thermal and non-thermal microwave effects Chem. Soc. Rev. 34 164-78

[6] Kappe C O 2004 Controlled microwave heating in modern organic synthesis Angew. Chem., Int. Edn 43 6250-84

[7] Pert E et al 2001 Temperature measurements during microwave processing: the significance of thermocouple effects J. Am. Ceram. Soc. 84 1981-6

[8] Will $\mathrm{H}$ et al 2003 Multimode microwave reactor for heterogeneous gas-phase catalysis Chem. Eng. Technol. 26 1146-9

[9] Bogdal D et al 2003 Microwave-assisted oxidation of alcohols using Magtrieve(TM) Tetrahedron 59 649-53
[10] Will H, Scholz P and Ondruschka B 2004 Heterogeneous gas-phase catalysis under microwave irradiation-a new multi-mode microwave applicator Top. Catal. 29 175-82

[11] Stuerga D and Gaillard P 1996 Microwave heating as a new way to induce localized enhancements of reaction rate. Non-isothermal and heterogeneous kinetics Tetrahedron 52 5505-10

[12] Nüchter M et al 2005 Contribution to the qualification of technical microwave systems and to the validation of microwave-assisted reactions and processes Chem. Eng. Technol. 28 871-81

[13] Lukasiewicz M, Bogdal D and Pielichowski J 2003 Microwave-assisted oxidation of side chain arenes by Magtrieve Adv. Synth. Catal. 345 1269-72

[14] Bogdal D, Bednarz S and Lukasiewicz M 2006 Microwave induced thermal gradients in solventless reaction systems Tetrahedron 62 9440-5

[15] Moseley J D et al 2007 The importance of agitation and fill volume in small scale scientific microwave reactors Tetrahedron Lett. 48 6084-7

[16] Green D W and Perry R H (ed) 2008 Perry's Chemical Engineers' Handbook 8th edn (New York: McGraw-Hill)

[17] Pinet E 2009 Fabry-Pérot fiber-optic sensors for physical parameters measurement in challenging conditions J. Sensors 2009720980

[18] Diagne C, Idriss H and Kiennemann A 2002 Hydrogen production by ethanol reforming over $\mathrm{Rh} / \mathrm{CeO}_{2}-\mathrm{ZrO}_{2}$ catalysts Catal. Commun. 3 565-71

[19] Childs P R N, Greenwood J R and Long C A 2000 Review of temperature measurement Rev. Sci. Instrum. 71 2959-78 